\title{
CONGENITAL HYPERTROPHIC S'TENOSIS OF THE PYLORUS
}

\author{
BY \\ EDMUND CAUTLEY, M.D.Cantab., \&c. \\ PHYSICIAN TO THE BELGRAVE HOSPITAL FOR CHILDREN; ASSISTANT \\ PHYSICIAN TO THE METROPOLITAN HOSPITAL
}

Received January 24th-Read November 8 th, 1898

The condition illustrated by the cases described in this paper is one in which the pylorus of the infant is found post mortem to be represented by a well-defined, cylindrical thick-walled tube, with its lumen exceedingly small or completely occluded.

There are other malformations of the pylorus which may cause obstruction during infancy or in later life. Thus there may be complete atresia, as in the cases recorded by Neale (1) and Lesshaft (2) ; or there may be a simple narrowing of the orifice, which may or may not be surrounded by a ring-like thickening. Henschel's (3) cases, referred to below, and those recorded by Finkelstein (4) from Heubner's clinic appear to be instances of simple stricture. Other causes of obstruction, such as polypi of the mucous membrane, recorded by Goldenhorn and Kolatchewski (5), and carcinoma of the pylorus (6) in a child aged five weeks, may be regarded as pathological curiosities. 
The kind of stenosis under consideration is more common, although comparatively little attention has been paid to it, and is of considerable importance. Stress has been laid on congenital narrowing of the pylorus as an important factor in the pathology of the dilatation of the stomach in adults. It is by no means improbable that the condition of pyloric stenosis in adults, descrilued by Habershon (7) in 1862 as "fibroid degeneration of the pylorus," and by Lebert (8) in 1878 as " hypertrophic pyloric stenosis," is due to the progressive development of a similar condition in infancy.

In his Inaugural Address in 1879, Landerer (9) described cases of stenosis and hypertrophy of the pylorus, occurring in adults and older children, which he regarded as congenital in origin. One of his most typical cases was that of a man aged forty-five, who had suffered since infancy from dyspepsia, a tendency to vomiting, and troublesome swelling of the abdomen. Death resulted from general atrophy due to impaired nutrition, and post mortem simple stricture of the pylorus and a dilated stomach were found. Prof. Rud. Maier (10) at Freiburg in 1885, under whose auspices Landerer's paper had appeared, dealt with the subject in an exhaustive manner, and detailed the symptoms of thirty-one cases as persistent vomiting and dilatation of the stomach. The two youngest of his patients were twelve and sixteen years of age respectively. He considered that a degree of congenital stenosis is a frequent, if not the most frequent, though unrecognised cause of this condition. Demme (11) in 1881 recorded a case of dilatation of the stomach in a boy aged six and a half years, who had suffered from vomiting and constipation since birth. He ascribed it to a contracted cicatricial ulcer, but more probably it was due to a certain amount of congenital stenosis. Tilger (12) in 1893 described similar cases, almost all in adults. So far it does not appear at all clear that the hypertrophy of the pylorus in adults is secondary to the stenosis rather than the stenosis secondary to the hypertrophy. I 
am very much inclined to accept the latter view. To prove the connection between the hrpertrophic pyloric stenosis in adults and a similar condition in infancy, it is necessary to find evidence of such a condition in enrly life.

The first record of the affection in infancy is a report by Williamson (13) in 1841 on "A case of scirrhus of the stomach, probably congenital." The specimen was exhibited at a meeting of the Anatomical Society of Edinburgh, and was regarded by the members as scirrhus of the pyloric extremity of the stomach. The details of the case correspond with those of more recent date.

CASE 1.-Male, apparently healthy at birth. Vomiting came on in a few days, and death took place in five weeks from exhaustion. Post mortem the pylorus was found hard and indurated, the orifice barely admitting a small silver probe. The mucous membrane and the submucous cellular tissue were thickened, the latter so much so as to form almost the whole wall.

Williamson regarded the condition as a "peculiar hypertrophy or modification of the cellular tissue." $\mathrm{He}$ was not aware of any other case.

Dawosky (14) in 1842 reported a case which came under his observation in the previous year.

CASE 2.-Child aged nine weeks when first seen, apparently healthy at birth. It was satisfactorily breastfed for four weeks, and then vomiting occurred two or three times daily. The vomit consisted of curdled milk and mucus. The stools were small. Death took place in the tenth week from marasmus, preceded for some days by convulsions. Post mortem a large hard pyloric tumour the size of a "nut;" the lumen would hardly admit a probe.

He regarded it as a hypertrophy with induration of the submucous tissue. After this date no attention appears to have been attracted to this affection until Hirchsprung (15) of Copenhagen in 1888 recorded two cases. 
CASE 3.-Thora J-, youngest of three girls, born December 27th, 1880, at term, and apparently healthy. She was breast-fed and well until ten days after birth. Severe vomiting then came on, and she died on the thirtieth day. Constipation was a very prominent symptom. Post mortem the œsophagus was found dilated and its walls thickened, the wall of the stomach somewhat thickened throughout, and the pylorus represented by a firm cylindrical thickening, $2 \frac{1}{2} \mathrm{~cm}$. long, through the lumen of which only a moderately thick sound could be passed. All the layers, particularly the muscular, were hypertrophied, and the mucous membrane was thrown into six projecting parallel folds.

CaSe 4.-Nathalie O-, born April 13th, 1886, came under treatment on July 9 th of the same year. At two weeks of age she was put out to nurse and fed in various ways, but her digestion was always bad, and she vomited repeatedly. At first she had diarrhœa. Death took place at six months from tuberculosis. The pylorus formed a thick cylindrical swelling, $3 \mathrm{~cm}$. long, due to hypertrophy of the muscular tissue. The stomach was a little dilated, but not the esophagus. Vomiting was a pronounced symptom during the whole of the child's life, but the obstruction at the pylorus was not complete, an ordinary pencil could be passed through it.

In 1889 W. K. Peden (16) showed a specimen of this condition at a meeting of the Glasgow Pathological and Clinical Society.

Case 5.-A well-developed baby at birth. The three previous children were all great vomiters. Vomiting began three days after birth; it was persistent and characteristic; a large drink was immediately rejected, small ones were retained until a certain quantity had collected. No tumour could be felt. The tongue remained clean, the breath sweet, and the bowels confined, but not markedly so. The child died at the age of 
three months. Post mortem the pylorus formed a sausage-shaped thickening, with a lumen $5 \mathrm{~mm}$. in diameter, further narrowed by two longitudinal crest-like projections extending along the whole length of the hypertrophied portion.

In 1891 G. Newton Pitt (17) showed a similar specimen at a meeting of the Pathological Society of London.

CASE 6.-The child died at the age of seven weeks, having suffered from vomiting and constipation for three weeks. The pylorus was an inch long, and formed of hypertrophied muscle. The wall of the stomach was also thickened.

Henschel (18) in 1891 recorded four allied cases, one of which recovered.

(i) Male aged 16 months; had suffered with chronic gastric catarrh, habitual constipation, and temporary diarrhœa. The stomach was dilated and the pylorus thickened, but its lumen would admit the little finger.

The next three cases were all in one family.

(ii) Female aged 19 months. The parents had long suffered from gastric troubles. The child vomited everything for the first six months, and was constipated. It improved for a time, and died at two years from exhaustion and excessive vomiting. The stomach was found dilated and the pylorus thickened, the lumen admitting a thick lead pencil.

(iii) A sister died at 7 months with similar symptoms. No autopsy.

(iv) A brother suffered with vomiting, constipation, and tympanites. He got better, and was seen when two and a half years of age. A fourth child of this family died of tuberculosis, and had abnormalities of the pylorus.

None of these cases of Henschel's presented the typical thickening of the pylorus which I am considering. They are rather instances of partial narrowing of the pyloric orifice, and are valuable as indicating the liability 
of this orifice to congenital or infantile pathological changes.

Dr. John Thomson (19), of Edinburgh, published two cases in 1896 and a third in 1897. In the second paper he gave a valuable bibliography. These two papers have been very kindly placed at my disposal by the writer, and I take this opportunity of gratefully acknowledging my indebtedness to him.

CASE 7.-Male, apparently healthy at birth and for ten days after. Then continual vomiting until death on the twenty-eighth day from emaciation and exhaustion. Post mortem the esophagus and stomach were found dilated, the mucous membrane of the latter congested. The pylorus was thickened and elongated, its walls one sixth of an inch thick, and the mucous membrane thrown into folds. The lumen would admit probe-pointed scissors. The condition was due to hypertrophy of the circular muscular fibres.

CASE 8.-Male, apparently healthy at birth and for four weeks after. Then vomiting occurred almost every time he took the breast, and continued, in spite of weaning and various methods of feeding, until death, preceded by fits, in the tenth week. The bowels were moved regularly during the first seven weeks of life, but after that there was obstinate constipation. The post-mortem appearances were similar to those of the last case.

CAS: 9.-Female, apparently healthy at birth and breast-fed for a week. Diluted cow's milk was then given, and vomiting began at once and continued, occurring immediately if more than two ounces of food were given at a feed. Gradual emaciation. A small hard moveable tumour was sometimes felt in the epigastrium. Death resulted on the forty-seventh day, preceded by convulsions for five days. Post mortem the same appearances were 
found as in the other two cases, with the addition that the submucous connective tissue was much thickened.

Chr. Gran (20), of Christiania, in 1896 described three cases.

(v) Female, died at four months, after vomiting and diarrhœa for a month. Post mortem the stomach was found much dilated and the pyloric orifice constricted.

CASE 10.-An illegitimate female, first child of a healthy mother. Vomiting and diarrhœa began at two months. After that there were frequent vomiting and an inclination to constipation. Death took place in the fifth month from exhaustion due to diarrhœa and vomiting. The digestion of milk was found to be more imperfect than that of farinaceous fluids. The pylorus was thickened and contracted, its lumen measuring $3 \mathrm{~mm}$. in diameter. The thickening was due to hypertrophy of the muscular fibres, especially the circular ones.

Case 11.-Male child, died in the fourth month, after attacks of vomiting and diarrhœa. The stomach was found very dilated. The pylorus was thick, the muscle extremely strong and thick, and the lumen was constricted.

H. Finkelstein (21) published a paper in 1896 in which he refers to the cases of Hirschsprung, Henschel, and Gran, and records another.

CaSE 12.-Female, brought up on cow's milk from birth, had started vomiting within a few days. During the third month the vomiting became more frequent, and there was much wasting and constipation. A tumour could be felt, about $2 \mathrm{~cm}$. above and somewhat to the right of the umbilicus, when the child was three months old, and death took place a few days later. Post mortem the characteristic cylindrical thickening of the pylorus, forming a muscular "intermediate piece;" much swelling of the mucous membrane, almost occluding the lumen. 
$\mathrm{He}$ also refers to three cases from Heubner's clinic, which presented symptoms of this condition in early life. The diagnosis could not be verified, as the patients recovered.

De Bruyn Kops (22) in 1896 reported one case.

CASE 13.-Male, well nourished at birth, began vomiting some hours after, and died at the end of three weeks of emaciation and anasarca. The pylorus was of the size of a "marble," and of cartilaginous hardness; it was much hypertrophied and markedly stenotic.

F. Schwyzer (23) in 1896 reported one case.

Case 14.-Female, weighing over eight pounds at birth, thrived well on the breast for two weeks. Then occasional vomiting and repeated attacks of diarrhœa. Death in the tenth week. The pyloric tumour was $2.4 \mathrm{~cm}$. long, and the lumen admitted a small probe with difficulty.

Ashby (24) in 1897 published two cases.

Case 15.-An infant started romiting after being quite healthy for a week. Gradual emaciation, convulsions, and death. The characteristic hypertrophy and stenosis of the pylorus were found post mortem.

(vi) An infant, operated on successfully on the third day of life for imperforate anus, died on the fifth day from continued vomiting. Much pyloric stenosis and some hypertrophy of the surrounding muscle were found post mortem. The characteristic sausage-shaped tumour is not described as being present.

Case 16. - There is a specimen of the condition in the St. Bartholomew's Hospital (25) Museum (No. 1907a), presented by J. Raglan Thomas, M.D. It was obtained from an infant who began vomiting at the age of three weeks, and died from inanition at seven weeks. The child was healthy at birth. The pylorus presents the usual condition. The stomach wall is thickened and the 
œsophagus dilated. The mucous membrane of the stomach and pylorus is congested and swollen. Microscopically an overgrowth of unstriped muscular tissue. The thickening terminates abruptly on the duodenal side, and gradually tapers off towards the cardiac side of the stomach.

CaSes 17 and 18.-W. Soltau Fenwick (26), in his work on the "Disorders of Digestion in Infancy and Childhood," 1897, refers briefly to two cases which came under his notice at the Evelina Hospital. I can find no specimen of this condition in the museum of the Royal College of Surgeons.

The details of the two cases under my care are as follows :

CASE 19.-Henry Kendall T- attended as an outpatient at the Belgrave Hospital for Children on April 20th, 1897, aged 11 weeks.

The father and mother are alive and healthy. The mother had two children by her first husband, the second of which died. Patient is the fifth child by the second husband, the other four being alive and healthy.

The child was apparently healthy at birth and up to the age of five weeks, when it began to waste rapidly. The mother's account is somewhat vague and unreliable, but as far as can be ascertained vomiting began at the age of three weeks. It is insured, and all the other children also.

He was brought up on the breast for three weeks, and then on the breast and Mellin's food. He vomited everything, and was then tried on condensed milk and barley water; this also was vomited. The bowels have been obstinately constipated since birth, and only opened by enemata.

Physical examination.-Much wasting; head markedly dolichocephalic, fontanelles closed; inguinal hernia on the right side; tongue coated with a white fur, breath

vol. LXXXII. 
sour. Vomiting occurs after feeding, the vomit being sour. The bowels costive.

April 20th.-Profuse nasal catarrh. The mother gives the breast every two hours, and has enongh milk. Vomiting has taken place only once a day. Much flatulence. The bowels acted naturally yesterday, the stool being a good colour.

May 3rd.-The child cries more and is in pain. He vomits twice a day, bringing up a "quantity of thick material." The bowels have acted on alternate mornings as a result of half a grain of grey powder twice a day since his last attendance. The wasting has increased. $\mathrm{He}$ was admitted. Weight $7 \mathrm{lbs} .10 \mathrm{oz}$.

Course.-He gradually became weaker. He vomited every kind of food at varying intervals. Peptonised milk in small quantities was kept down for a couple of days, but he lost weight on it. The bowels acted sometimes without the aid of medicine, the stools being small and often greenish. The temperature ranged between $96^{\circ} \mathrm{F}$. and normal, being generally at the lower level. After May 8th the temperature was constantly below $97^{\circ} \mathrm{F}$., and the vomiting became more frequent. Death resulted from exhuustion on May 12th. There was a loss of $6 \mathrm{oz}$. during the first three days after admission, but after that the weight remained practically stationary.

Post-mortem.-Great emaciation. Head large and heary. All the visceral organs appeared healthy with the exception of the stomach and pylorus. The pylorus was represented by a firm thick sausage-shaped swelling, an inch in length, distinctly limited above and below. Looked at from the duodenal side it has a remarkable resemblance to the os uteri. The stomach was much dilated, and on squeezing it firmly, pressing the contents towards the pylorus, a small quantity could be forced through into the duodenum. A small amount of food was found in the intestines.

On opening the stomach the contents were found to consist of partially digested food and mucus. The 
pyloric orifice was very small, and would only admit a probe. On opening the pylorus by an incision prolonged from the lesser curvature of the stomach the wall was found very thick, about three-eighths of an inch; the mucous membrane was thickened, especially towards the duodenal end, where it formed almost a definite capsule, thinning off on the cardiac side into the mucous membrane of the stomach. On the side corresponding with the continuation of the greater curvature of the stomach the mucous membrane was thrown into a thick ridge-like fold, continuous throughout the whole length of the pyloric tumour. The resistance on section of the wall was almost as firm as, and somewhat similar to that experienced in cutting through a scirrhous carcinoma of the pylorus. To the naked eye the main cause of the thickening is a remarkable increase in the circular muscular fibres, this thickening being most pronounced on the duodenal side and tapering off towards the cardiac side, but nevertheless ending fairly abruptly on that side. It is perfectly easy to see the limit of the hypertrophy. . It is very evident that the thickening of the mucous membrane is an important factor in the production of a more or less complete obstruction.

Microscopical examination confirms the above observations. The mucous and submucous coats are markedly thicker than normal, but the great factor in the production of the sausage-shaped swelling is an extensive hypertrophy of the circular muscular fibres.

A further abnormality was found in the shape of a large cavity in the right hemisphere of the brain, somewhat irregular, lined with smooth walls, and containing clear fluid and a few flakes of lymph. This cavity did not appear to communicate with the ventricle, though at one time it may have done so.

It is curious, when we consider the rarity of this condition, that the second case came under my notice a few days after the death of the first child. For the clinical 
notes and the details of the post-mortem I am indebted to my house physician, Mr. G. S. Haynes.

$\mathrm{C}_{\text {ASE }}$ 20.-John I- at the age of seven weeks was brought to the hospital on May 17th, 1897, for wasting. He was brought by a "friend," paid to look after the child by the mother, who was out at work as an ironer. This friend stated that the child was "a fine baby born." He had been wasting for a week, and vomited invariably after feeding. He was fed irregularly on the breast and condensed milk. The stools were green and offensive.

On May 19th the child was brought by the grandmother, who could give no information about it.

On May 20th at 6 a.m. he died "in a fit." The instructions as to feeding had not been carried out. The coroner, having been notified, ordered a post-mortem examination.

According to subsequent information obtained from the mother, the child was the youngest of four, of whom one other is dead. The father suffers from rheumatic gout, and is in the infirmary. The baby was not weighed at birth, but was a fairly good size. During the first week of life he vomited frequently, although only breastfed. At the age of three weeks he was taken to the Western Dispensary and treated there for three weeks. As he did not improve he was taken to the Westminster Hospital, where cow's milk and barley water were prescribed for him. When brought to the Belgrave Hospital he was cold, very emaciated, but had a fair pulse.

Post-mortem.-Extreme emaciation. On opening the abdomen the distended stomach was seen extending obliquely from the left hypochondrium to the right of the umbilicus. The splenic end was in contact with and adherent to the spleen, which was somewhat large. The stomach contained about four ounces of darkish grey fluid, rather slimy from the presence of an excess of mucus, and blackish particles of matter. Its mucous membrane was pale and swollen. The pylorus presented the same 
characteristics as in the other case, though not quite so marked. It formed an elongated sausage-shaped tumour about an inch long, and its lumen was impervious. The small and large intestines were absolutely empty. The appearances on section to the naked eye and on microscopical examination were the same as in the previous case. No other abnormality was present.

\section{Summary.}

Here are no less than twenty undoubted cases in which the pylorus presented a remarkable condition of muscular hypertrophy and stenosis. There are six cases (Nos. 1-6) which presented conditions of stenosis but not the peculiar hypertrophy, and four others which presented fairly characteristic symptoms and recovered. The cases have been collected from various parts of the world, and it is noteworthy that all but two have been recorded during the last ten years, and no less than eleven (including Fenwick's cases) during the last two years. It is evident that the condition is not so extremely rare as might be supposed. In all probability mans more instances of it would be found if post-mortem examinations were invariably made on infants dying from romiting and marasmus. It is distinctly the cause of that symptomatic disease " marasmus" in some cases.

\section{General Description.}

The most definite clinical symptom of this affection consists in constant vomiting without apparent cause, especially in the absence of any sign of gastritis or enteritis. The next important symptom is more or less constipation. Gradually the child emaciates, and death results from exhaustion consequent on general failure of nutrition, and is sometimes preceded by convulsions.

Family history. - Nothing has been noted in the parents as likely to account for the condition. There appears to 
be no indication whatever of any connection with inherited syphilis. As a general rule the other children of the family are healthy. Possibly there may be a predisposition in certain families. Thus in Peden's case it was noted that the three previous children were all great vomiters, and three of Henschel's allied cases occurred in the same family. In the two cases under my own care there was no indication in the family history of such a predisposition or of an inherited ætiological factor.

Sex.-It is not to be expected that one sex should be more liable than another. About lialf the patients are male and half are female.

Condition of the child at birth.- In every case it has been noted that the infant was apparently healthy at birth, or, to use a common expression, was " a fine baby born." There is no indication at this period of the presence of the pyloric affection.

Date of onset.-This varies considerably. The first symptom may be noted a few hours after birth (Case 13), or may not be noted for a month or more. As a general rule it is rare for the vomiting not to commence during the first month of life. No doubt the actual date depends upon the degree of stenosis present.

Mode of onset. - This invariably takes the form of vomiting. Until the child is sick there is no indication that it is not in perfect health, unless it suffers from a certain amount of flatulent dyspepsia and constipation. Both the latter symptoms usually follow the romiting in point of time.

Characteristic symptoms and physical signs.-1. Vomiting.-At first this may only occur at fairly long intervals, once a day, for instance, a considerable quantity of food being pumped up when the stomach has become over-distended. Gradually it becomes more and more frequent, several times a day. It is persistent and very characteristic, A large drink is invariably rejected almost immediately. but small meals may be retained a considerable time, after which several are vomited at unce. In the first of my 
cases on one occasion there was no vomiting for fortyeight hours, but the amount of food taken by the child was not enough for the maintenance of nutrition; the child lost weight, and its temperature was constantly subnormal. In the later stages vomiting occurs on the administration of the smallest quantities of food.

At first the vomiting may be mistaken for the simple regurgitation of food so common in infants. Later on such an error cannot be made if the child is under skilled observation. The act is so much more forcible, more like the vomiting of older children, and it apparently causes a very definite amount of pain. Nevertheless the infant is most comfortable when the stomach is empty.

The nature of the food does not usually influence the vomiting. It depends mainly on the amount. To a certain extent soluble foods, such as saccharine solutions, and pre-digested foods such as peptonised milk, are kept down better than ordinary milk. Thus in my first case I found that peptonised milk was retained best, at any rate for a period of two days. Gran found in one case (No. 10) that thin farinaceous fluids were retained better, and were more perfectly digested than milk, probably for the simple reason that the latter is a much more complicated fluid. The vomited matter consists at first entirely of the food given, more or less changed by the action of the gastric juice. It is consequently composed of sour coagulated milk, this being the common diet in infancy. Frequently, especially in the later stages of the illness, there is a considerable quantity of mucus mixed with it.

There is no bile in the vomit. This is a very important fact, for it indicates that the seat of obstruction is above the entrance of the common bile-duct into the duodenum.

If the stomach be washed out and a test feed inserted, it will be found possible to recover the whole or a greater part of the feed in three or four hours' time. Gran made some interesting observations (loc. cit.) under such circumstances. This is a valuable test of the presence of 
pyloric obstruction, for it is generally accepted that the stomach of infants is emptied in about two hours' time.

2. The bowels.-Constipation, though a common symptom, is not as invariably present as would be expected. In the early stages, and even in later stages when the obstruction is not complete, there may at times be diarrhœa. This is due to irritation from decomposing food retained in the stomach, the irritating products passing on into the intestines. Generally the stools are small, and present no obvious alteration. In some cases constipation is a very marked symptom, the bowels not being open for eight days (Case 3), or only open by means of enemata (Case 19). Even during the last fortnight of life there may be diarrhœa, but, as a rule, there is obstinate constipation.

3. The tongue.-The character of the tongue varies according to the absence or presence of secondary gastric catarrh. It may be clean throughout the illness (e. $g$. Case 5), and at the same time the breath may be quite sweet. Or the breath may be sour and the tongue coated with a thin white fur.

4. The abdomen.-On inspection there are no signs of intestinal obstruction. The abdomen is flat and thin. There may be a distinct swelling in the epigastrium and the usual signs of a dilated stomach. On the other hand, it must be remembered that vomiting takes place. with such great ease in infants that there may be no very definite increase in the size of the stomach. A dilated stomach may also occur in conditions unconnected with pyloric obstruction.

It may be possible to demonstrate the presence of a tumour in the region of the pylorus. Finkelstein demonstrated an enlarged hard pylorus (Case 12), and Thomson found a hard moveable tumour in the epigastric region (Case 9) during life.

5. General condition.-'There are all the signs of starvation. The child is very wasted, and continues wasting. The surface of the body is cold, and the tem- 
perature is subnormal. The pulse is frequent, small, and weak. The child lies in a condition of lethargy, with half-open eyes, and takes no interest in its surroundings. It occasionally cries from pain, and rouses a little to vomit. Food is not taken with avidity, and is often refused.

\section{Morbid Anatomy.}

There is great emaciation. All the organs of the body are free from the signs of disease with the exception of the alimentary tract. In one case (No. 4) tuberculosis of the lung and secondary dissemination were present and caused death, the stenosis not being at all extreme although the pyloric hypertrophy was well marked.

The osophagus may or may not be dilated, dilatation depending on the degree and duration of the obstruction.

The stomach generally presents more or less dilatation, sometimes extreme, in which case its walls are thinned. The contents consist of undigested food and mucus, and occasionally small particles of blood. The mucous membrane is normal unless there has been -co-existent gastric catarrh, in which case the ordinary signs of this condition will be found. In some infants the muscular walls of the pyloric end of the stomach have been found somewhat hypertrophied. I could not satisfy myself that such hypertrophy was present in my cases.

The pylorus is represented by a very definite tumour, which has been described as an "intermediate piece," a "cylindrical swelling," and as a "sausage-shaped tumour." It varies a little in size, but may be taken roughly as about the size of the last joint of the little finger, and about an inch long. On external examination with the fingers the limits of the tumour can be definitely fixed both on the duodenal and the gastric side; to the touch it ends more abruptly on the duodenal side, but there is also a very distinct limit to it on the gastric side. It is very firm and hard. If the duodenum is laid open and the pylorus looked at from that aspect, it 
resembles the os uteri in having a small central orifice, apparently occluded, and a thick, smooth, ring-like surrounding wall, and it projects into the duodenum in much the same manner as the os uteri projects into the vagina. The appearance from the stomach side is rather funnel-shaped, and the occlusion of the lumen by the puckered mucous membrane is more distinet.

To the naked eye the occlusion of the lumen is complete in some cases, and it is not possible to squeeze the fluid contents of the stomach through it. Even in these instances a fine probe can be passed through the whole length of the canal. This occlusion of the lumen is due to the contraction of the hypertrophied muscular tissue forming its wall, and is assisted by the thickening of the mucous membrane, which is thrown into one or more longitudinal ridge-like folds extending the whole length of the thickening.

On longitudinal section it can be seen very clearly by the naked eye that the tumour is simply a thick-walled tube, and it is evident that the main cause of the thickness of the wall is the hypertrophy of the muscular fibres forming the middle coat. This hypertrophy is most marked and ends most abruptly on the duodenal side, forming a rounded swelling, and it gradually diminishes though still ending fairly abruptly on the gastric side. The mucous membrane and submucosa appeared definitely thickened in my two cases. The single ridgelike fold in the specimen from Case 19 is extraordina:ily marked. On looking at the cut surface, the mucous membrane is seen to form a very definite capsu?e, especially thick over the intra-duodenal portion, and thinning off gradually into the mucous membrane of the stomach.

Microscopical examination confirms the above observations with the exception that it shows the mucous membrane is not thickened, and that the apparent thickening is only due to the contraction of the walls of the tube. The hypertrophy of the circular muscular 
fibres is very marked, and there is a moderate increase in the amount of intermuscular connective tissue. The external longitudinal muscular layer is a little thicker than normal. There is no clange in the serous covering and no sign of inflammatory action.

These observations practically agree with those of previous observers. Finkelstein, however, states that the thickening in his case (No. 12) was due to hypertrophy of the longitudinal muscular fibres, and gives a diagrammatic representation of the specimen in his paper. I am inclined to think that the appearance is due to the section having been cut obliquely.

Pathology.-The condition is definitely one of hypertrophy of the circular muscular fibres which are normally present in the pylorus. In considering the origin of the hypertrophy we must bear in mind the following facts.

1. It is a pre-natal condition, for the extent of the hypertrophy is such as could not have occurred during the few weeks of extra-uterine life. In several cases the symptoms were observed during the first week of life.

2. There is plenty of time for the hypertrophy to occur before birth, for the first indication of a pylorus is found during the third month. It is formed from the fore-gut, and the circular muscular fibres are derived from the mesoblast.

3. Normally the pylorus of an infant is represented by a small circular orifice, surrounded by a slight increase in the circular muscular fibres belonging to the general system of circular muscular fibres of the alimentary canal. Externally it can be felt as a slightly thickened ring. It is evident that in the condition under consideration the amount of hypertrophy is relatively enormous.

The general explanation of hypertrophy is increased work. In the present instance it is difficult to find the source of an increase in work. 'Thomson, in his second paper, puts forward the theory that " the essential lesion is not a muscular but a nervous one-a functional disorder of the nerves of the stomach and pylorus leading to ill- 
co-ordinated and therefore antagonistic action of their muscular development." $\mathrm{He}$ regards the affection as a "congenital gastric spasm," or "congenital pyloric spasm."

Another theory which might be put forward is that it is due to a simple redundancy of fotal growth. Nature, in her extreme anxiety to provide an efficient pyloric sphincter, has over-exerted herself, and produced too great "quantity of muscular tissue. It is useless to discuss theories in the present state of our knowledge of the affection, and I prefer to retain a name which indicates the anatomical condition, and thus at once brings to mind the symptoms likely to arise from that condition.

Diagnosis and prognosis.-The diagnosis depends on the characteristic vomiting, the absence of bile from the vomit, the presence of constipation, a history of the occurrence and persistence of the symptoms without definite cause and in spite of treatment, and finally in the presence of a cylindrical moveable tumour in the region of the pylorus.

'The affection is especially liable to be confused with the simple regurgitation of food in infants and with simple gastric catarrh. The character of the vomiting distinguishes it from the former, and the presence of a clean tongue and sweet breath will eliminate the latter. The presence of a tumour is almost diagnostic, for other forms of tumour in this region at an early age are extremely rare, e.g. an enlarged gland is rarely sufficiently definite, and if present would hardly be likely to cause such symptoms.

The prognosis is necessarily bad, especially if the tumour is large enough to be felt. Cases of recovery from symptoms characteristic of the disease have been referred to, but the diagnosis must necessarily remain doubtful. The duration of life depends upon the severity of the stenosis. The shortest period recorded as elapsing between the onset of the vomiting and a fatal termination is serenteen days. The longest is six months (Case 4), 
but here the cause of death was tuberculosis. Four months of life is about the average for infants thus affected. In the slighter instances of this affection it is reasonable to suppose that the symptoms may not be of much moment, and may be limited to dyspepsia with an occasional attack of vomiting. It is quite possible that such cases do exist, and that they terminate in later life from dilatation of the stomach, hypertrophic stenosis of the pylorus being found post mortem.

Treatment.-If the tumour can be felt, and an accurate diagnosis thus arrived at, the most rational treatment consists in operative measures. Three courses would be open to the surgeon. The pylorus might be dilated, or it might be excised, or a communication might be made between the stomach and the small intestine. The last method would probably be the most satisfactory.

Apart from surgical treatment, only palliative measures are available. Drugs are useless to relieve the vomiting. Lavage of the stomach is of temporary benefit by washing out mucus and decomposing food, thus allowing the child a better chance of absorbing some of its next meal. Small quantities of food should be given at a time, and the food should be pre-digested and of simple composition. Not much can be expected from these measures, for in infants the stomach has not a capacity for the digestion or absorption of more than a small amount. Schwyzer kept his patient alive for a fortnight by rectal feeding.

I cannot claim to have added new facts to our knowledge of this uncommon affection, nor to have devised new methods of diagnosis or treatment. As far as I am aware, no paper has been read on this subject before a medical society in London, and I have taken the opportunity afforded me by the two cases which came under my notice of bringing the subject before you, with the object of eliciting the experience and the views of more competent authorities on this very curious and fatal condition. 


\section{References.}

1. Neale. - ' Lancet,' June 7th, 1884.

2. Lesshaft. - Jahr. f. Kinderheilk.,' xxii, 1885, s. 264.

3. Henschel._' Archiv f. Kinderheilk.,' xiii, 1891, s. 32 .

4. Finkels'tein.—'Jahr. f. Kinderheilk.,' xliii, 1896, s. 105.

5. Goldenhorn and Kolatchewski.- 'Berliner Klinische Wochenschrift,' 1888, Bd. xxv, s. 51.

6. Stern.-_'Deutsch. med. Wochenschr.,' 1892, s. 494.

7. Habershon.- - Diseases of the Abdomen,' 1862.

8. Lebert.- 'Die Krankheiten des Magens,' Diss., Tübingen, 1878.

9. Landerer.- 'Ueber angeborene Stenose des Pylorus,' Diss., Tübingen, 1879.

10. Marke.- 'Virchow's Archiv,' 1885, Bd. cii, s. 413.

11. Deмme.- 'Jahresbericht des Jenner'schen Kinderspitals,' 1881, Bd. xix.

12. Tilakr.—'Virchow's Archiv', 1893, Bd. cxxxii, s. 290.

13. Williamson.- - Edin. 'Monthly Journ. of Medical Science,' 1841, i, 23.

14. Dawosky. - 'Archiv. général de Médecine,' sér. 4, t. ii, p. 93, 1843 ; 'Caspar's Wochenschr.,' 1842, No. 7.

15. HirschspRUNG.- ' Jahr. f. Kinderheilk.,' 1888, Bd. xxviii, Heft 1, s. 61.

16. Peden.- ' Glasgow Medical Journal,' 1889, i, 416.

17. Pitr.- 'Lancet,' 1891, ii, 931, and 'Trans. Path. Soc. Lond.,' 1892, p. 63.

18. Henschet.-'Archiv f. Kinderheilk.'’ 1891, Bd. xiii, s. 32 .

19. Thomson.- 'Edin. Hosp. Reps.,' 1896, vol. iv, p. 116 ; ' Scottish Med. and Surg. Journ.,' June, 1897.

20. GRAN.—'Jahr. f. Kinderheilk.'’ 1896, Bd. xliii, Heft. 1, s. 118.

21. Finkelstein.-Loc. cit.

22. Kops.- 'Nederlandsch Tijdschrift voor Genees- 
kunde,' Amst., 1896, No. 25 ; 'Brit. Med. Journ.,' Epitome, Jan. 30th, 1897, No. 103.

23. Schwyzer. - N New York Med. Journ.,' 1896, ii, 674, and 'Deutsch. med. Monatsschr.,' 1895, No. 6.

24. Ashby.- ' Archives of Pediatrics,' July, 1897, p. 498.

25. St. Bartholomew's Hospital Museum, No. 1907a.

26. Fenwick.- Disorders of Digestion in Infancy and Childhood,' 1897.

(For report of the discussion of this paper, see 'Proceedings of the Royal Medical and Chirurgical Society,' Third Series, vol. xi,. p. 14.) 